\title{
Correlates of Use of Antifracture Therapy in Older Women with Low Bone Mineral Density
}

\author{
Kathryn M. Ryder, MD, MS, ${ }^{7}$ Ronald I. Shorr, MD, MS, ${ }^{7}$ Frances A. Tylavsky, DrPH, ${ }^{1}$ \\ Andrew J. Bush, $P h D,{ }^{1}$ Douglas C. Baver, MD, MPH, Eleanor M. Simonsick, PhD, ${ }^{3}$ \\ Elsa S. Strotmeyer, PhD, MPH, ${ }^{4}$ Tamara B. Harris, MD, MS, ${ }^{3}$ for the Health ABC Study \\ ${ }^{1}$ The University of Tennessee Health Science Center, Memphis, TN, USA; ${ }^{2}$ The University of California, San Francisco, CA, USA; ${ }^{3}$ The National \\ Institute on Aging, Bethesda, MD, USA; ${ }^{4}$ The University of Pittsburgh, Pittsburgh, PA, USA.
}

\begin{abstract}
BACKGROUND: Guidelines exist for treatment of low bone mineral density (BMD). Little is known about patient characteristics associated with use of treatment.
\end{abstract}

OBJECTIVES: To determine patient-related correlates of medication use following screening dual x-ray absorptiometry (DXA) of older adults.

DESIGN: Secondary analysis of a prospective cohort study.

SETTING: Pittsburgh, PA and Memphis, TN.

PARTICIPANTS: Community-dwelling women between the ages 70 and 79 years enrolled in the Health, Aging, and Body Composition (Health $\mathrm{ABC}$ ) Study.

MEASUREMENTS: Risk factors for fracture and BMD of the hip were assessed at baseline. Patients and their community physicians were supplied the results of the DXA scan. Prescription and over-thecounter medication use was collected at annual exams for 2 years.

RESULTS: Of 1,584 women enrolled in Health ABC, 378 had an indication for antifracture therapy and were not receiving such treatment at baseline. By the second annual follow-up examination, prescription antiresorptive medication was reported in 49 (13.0\%), whereas 65 $(17.2 \%)$ received calcium and/or vitamin D supplementation. In adjusted models, the strongest predictor for use of any antifracture medicine was presence of osteoporosis [vs osteopenia, odds ratio (OR), 2.9 (1.7 to 4.7)], white race [OR, 2.6 (1.5 to 4.8)], and receipt of the flu shot [OR, 2.2 (1.3 to 3.8)]. Neither a history of falls nor prior fracture was associated with use of antifracture medications.

CONCLUSION: Even when physicians of study participants were provided with DXA scan results, $70 \%$ of older high-functioning women with an indication for therapy did not start or remain on an antifracture therapy. Substantial room for improvement exists in fracture prevention following a diagnosis of low BMD-especially among women with a history of falls, prior fractures, and among black women.

KEY WORDS: osteoporosis; guidelines; prevention.

DOI: $10.1111 /$ j.1525-1497.2006.00468.x

J GEN INTERN MED 2006; 21:636-641.

Conflict of interest

Financial disclosures:

Dr. Ryder has received grant funding from Eli Lilly for a different study. Dr. Shorr: None

Dr. Tylausky: None

Dr. Bush: None

Dr. Bauer: None

Dr. Simonsick: None, federal employee

Dr. Strotmeyer: None

Dr. Harris: None, federal employee

Address correspondence and requests for reprints to Dr. Ryder: Department of Medicine, Division of General Internal Medicine, 66 N. Pauline Street, Suite 381, Memphis, TN 38163 (e-mail: kryder@utmem.edu).
There is a dramatic increase in the prevalence of low bone 1 mineral density (BMD) and fracture with age, such that over $50 \%$ of white women older than 80 years have osteoporosis ${ }^{1}$ and have a 10 -year hip fracture rate of nearly $16 \% .^{2}$ There is strong evidence that antiresorptive drug therapy increases BMD and reduces the risk of fractures. ${ }^{3-6}$ The availability of effective interventions to prevent fracture has resulted in recommendations for osteoporosis screening and treatment by various professional societies and government institutions for over a decade. ${ }^{7-11}$

Despite the evidence and recommendations, prevention and treatment of osteoporosis remains low. Following acute fragility fracture, there is a low rate of intervention to diagnose $^{12,13}$ and treat ${ }^{14}$ underlying osteoporosis. Additionally, once treatment of osteoporosis has been initiated, there is a high rate of discontinuation of therapy. ${ }^{15}$ The characteristics of women for whom osteoporosis therapy is recommended by a physician, or who self-select to use medication, have not been well studied. We used the Health, Aging and Body Composition (Health $\mathrm{ABC}$ ) study to investigate the use of antifracture medications in a group of women for whom the National Osteoporosis Foundation (NOF) would recommend therapy. ${ }^{11}$ We hypothesized that demographic factors, measures of comorbidity (higher number of medications, presence of dementia, and a higher number of medical conditions known to be linked to mortality), measures of mobility (inability to rise from a chair and low walking speed), not receiving preventive care (flu shot or mammogram), and low self-efficacy would be associated with lower use of antifracture medication. Because guidelines and therapeutic trials for osteoporosis have addressed mainly white women, we assessed whether race had an impact on medication use.

\section{METHODS}

\section{Participants}

Health $\mathrm{ABC}$ is a longitudinal cohort study of 3,075 highfunctioning older (ages 70 to 79 years) men and women from Memphis, TN and Pittsburgh, PA. The primary aim of Health $\mathrm{ABC}$ was to investigate the relationship between changes in body composition and functional decline. ${ }^{16}$ The current study is an analysis of data from the baseline exam in 1997 through the second annual follow-up exam completed in 2000.

All Health ABC participants underwent a dual x-ray absorptiometry (DXA) examination at the baseline exam, the results of which were given to participants and their physicians

Manuscript received August 31, 2005

Initial editorial decision October 14, 2005

Final acceptance February 15, 2006 
(96\% of participants designated a physician recipient of study findings). The DXA report included the BMD at the total hip and femoral neck, as well as the corresponding $T$ - and $Z$ scores. The printout included general recommendations to improve BMD (i.e., stop smoking, ensure adequate calcium and vitamin D intake). Per study protocol, participants with osteoporosis at the total hip ( $T$-score of $\leq-2.5$, corresponding to $\mathrm{BMD} \leq 0.637$ or $\leq 0.641 \mathrm{~g} / \mathrm{cm}^{2}$ among white and black female participants, respectively) received an additional "alert letter," which reviewed the consequences of osteoporosis and risk factors for low BMD. The alert letter recommended that participants discuss the findings with their physician. All procedures were conducted in accordance with the ethical standards of the Institutional Review Boards of the participating institutions, which approved the protocol and the consent forms.

For this analysis, we included women who were not using drugs to treat osteoporosis and were candidates for osteoporosis drug therapy according to guidelines established by the NOF in 1998. The NOF is a major national volunteer health organization dedicated to bone health that was established in 1984, and in 1998 published national guidelines for screening and treatment for osteoporosis. The NOF recommends "drug treatment of osteoporosis," including counseling regarding exercise and calcium and vitamin D intake, as part of the treatment program for women with the following: a prior hip or vertebral fracture, a BMD $T$-score below -2 by central DXA, or a $T$-score below -1.5 by central DXA with at least 1 risk factor (prior fracture as an adult, history of fracture in a first-degree relative, smoking, and body weight under $127 \mathrm{lbs}$ are the major risk factors considered by the NOF). ${ }^{11}$ In our cohort, we collected data regarding all these risk factors except for family history.

Of 1,584 women enrolled in Health ABC, 1,572 (99.2\%) had a technically valid DXA of the hip at the baseline exam. We excluded women using oral steroids $(n=15)$ and those with no follow-up medication data in the following 2 years $(n=41)$, leaving 1,516 women. This high follow-up rate over 2 years was secondary to the use of retention tools, including $\$ 20$ honoraria for attending visits, transportation to and from the clinic site, and annual participant appreciation events. Additionally, if a participant could not attend the study visit, a home visit was conducted. The Core Home Visit included the interview, medication inventory, and a subset of measurements.

Among the 1,516 women with follow-up, we excluded 774 (51.1\%) because they did not have an NOF indication for therapy, and $364(24.0 \%)$ because they were already using antifracture therapy, including calcium and/or vitamin D. Thus our study included 378 high-functioning older women with 1 or more NOF criteria for osteoporosis treatment who were not using these agents at the baseline Health $\mathrm{ABC}$ examination (Fig. 1).

\section{Measurements}

Bone mineral density was measured using a Hologic QDR Model 4500 fan-beam densitometer (Waltham, MA), using software version 8.21 for the fan beam. The DXA Quality Assurance Manual for the Health ABC Study was used to standardize patient positioning and scan analysis. National

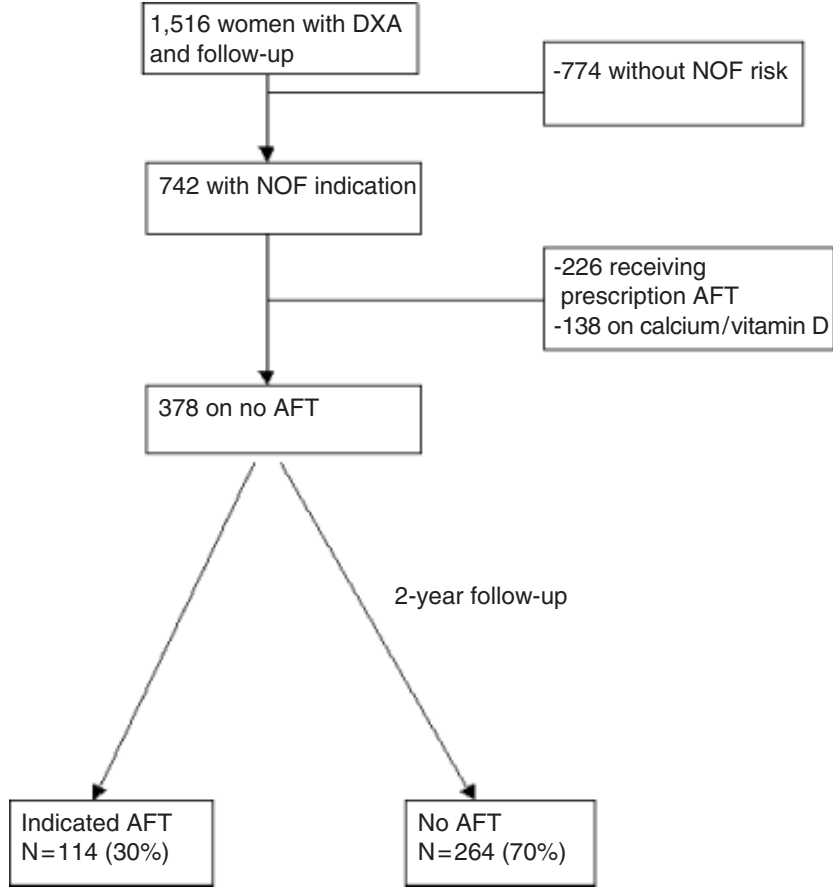

FIGURE 1. Women included in the current secondary analysis of the Health, Aging and Body Composition cohort. Of 378 women with an National Osteoporosis Foundation indication for antifracture therapy and not on therapy at baseline, only 30\% initiated some form of treatment by 2 years. AFT, antifracture therapy; DXA, dual x-ray absorptiometry.

Health and Nutrition Examination Survey adjusted $T$ scores were derived for the hip.

To identify prescription, nonprescription, and herbal therapy use, Health $\mathrm{ABC}$ participants were instructed to bring in bottles containing all prescription and over-the-counter medications (including vitamins and supplements) used in the 2 weeks before the visit. Trained research assistants transcribed medication and supplement information from the bottles. Medications were coded using the Iowa Drug Information System (IDIS) ingredient codes. ${ }^{17}$

We defined antifracture therapy as supplemental calcium and/or vitamin D or a prescription antiresorptive agent (oral bisphosphonate, calcitonin, oral or transdermal estrogen, or raloxifene). Initiation was defined as the new use of one or more of these by the third annual Health $\mathrm{ABC}$ exam.

\section{Analysis}

SAS statistical analysis software for Windows (version 9.1) was used for all analyses (SAS Institute, Inc., Cary, NC). Student's $t$ test and Fisher's exact $\chi^{2}$ statistics were used for univariate analysis. All probability values were 2 -sided. Logistic regression was used for multivariable adjustment. Covariates included race, income, prescription drug insurance, number of medications above/below the median, presence of osteoporosis at a hip site, educational attainment, selfreported history of falls, difficulty standing without the use of arms, use of preventive interventions (flu shot, mammography), gait speed, diminished cognitive function (a score under 80 on the Teng Mini Mental Status Exam [3MS], ${ }^{18}$ and the 
Charlson comorbidity index. ${ }^{19}$ To assess self-efficacy/personal mastery, participants were asked how strongly they agreed with the statements: "I can do anything I set my mind to" and "I often feel helpless." The participants who agreed strongly with the statement "I often feel helpless" or disagreed strongly with the statement "I can do anything I set my mind to" were classified as having low self-efficacy.

\section{RESULTS}

\section{Baseline Characteristics}

The 378 women in this analysis had the following indications for antifracture therapy: $297(78.6 \%)$ had a $T$-score less than -2 at either site, $74(19.6 \%)$ had a $T$-score less than -1.5 and at least 1 clinical risk factor, and 7 (1.9\%) were included because of a self-reported prior fracture of the hip or vertebrae. Risk factors for fracture (participants could have more than 1) were a fracture after the age of 45 years (161 participants), weight less than 127 lbs (123 participants), and current smoking (67 participants). Table 1 shows other characteristics of the 378 women.

There were $9(2.3 \%)$ additional women that met inclusion criteria but had no follow-up at the second and third exam. Baseline characteristics of women without follow-up were not different for all variables investigated.

\section{Use of Antifracture Therapy}

By 2 years of follow-up, 114 (30.2\%) of the 378 participants reported use of an antifracture therapy. Only 49 (13.0\% of the group) started a prescription antiresorptive agent. This number was only slightly higher in the subgroup of women with osteoporosis; only $42.3 \%$ reported use of any antifracture medicine, which was prescription therapy in only $16.9 \%$.

The prescription therapies were oral or percutaneous estrogen (34.5\% of new prescriptions), bisphosphonates (33.3\%), calcitonin (13.4\%), or raloxifene $(8.8 \%)$. The remainder of those on antifracture therapy started only calcium and vitamin D.

Table 1. Characteristics of 378 Women Included in the Analysis

\begin{tabular}{lc}
\hline \hline Variable & $\boldsymbol{N}(\%)$ \\
\hline Race & \\
White & $180(48)$ \\
Black & $198(52)$ \\
Age, y & $73.9 \pm 2.8$ \\
Income $<25,000$ & $273(72)$ \\
Drug coverage & $220(58)$ \\
Education $\geq$ HS & $275(73)$ \\
Osteoporosis $(T$-score $\leq-2.5)$ & $142(38)$ \\
$T$-score $\leq-2$ & $297(79)$ \\
Charlson score $\geq 2$ & $80(21)$ \\
Walk speed $<1$ m/min & $121(32)$ \\
Difficulty rising & $44(12)$ \\
Previous fracture & $161(43)$ \\
Fall/12 mo & $94(25)$ \\
Dementia (3MS $<80$ ) & $48(13)$ \\
Medication number, median (interquartile range) & $4(2$ to 6$)$ \\
Low efficacy & $17(4.5)$ \\
Flu shot/12 mo & $218(58)$ \\
Mammogram ever & $333(88)$ \\
\hline
\end{tabular}

HS, high school, 3MS, Modified Mini-Mental State.
Multivariable Correlates of New Use of Antifracture Therapy. The mean age of participants was $73.9 \pm 2.8$. Neither older age, a higher number of medications, difficulty standing up from a chair, slow walking speed, the presence of dementia nor a higher number of comorbid conditions was associated with lower antifracture medicine use (Table 2). Notably, neither a history of falls or of prior fracture increased the receipt of antifracture therapy. The multivariable-adjusted predictors of initiating any fracture-reduction therapy were $T$ score $\leq-2.5$ (odds ratio [OR] 2.9 [1.7 to 4.7]) at any hip site, white race, with an OR of 2.6 ( 1.5 to 4.8 ), and receipt of the flu shot in the past 12 months (OR 2.2 [1.3 to 3.8]).

Racial Differences in Initiation of Therapy. Whereas $43.9 \%$ of white women with a NOF indication for therapy initiated calcium and/or vitamin D or a prescription antiresorptive therapy, only $17.7 \%$ of black women did $(P<.001$ on multivariable analysis). NOF criteria were: a $T$ score $\leq-2$ (150 white, 147 black); or a $T$ score $<-1.5$ with a risk factor (30 white, 44 black). The 7 remaining women had a previous spine or hip fracture. Osteoporosis at the total hip or femoral neck was seen in 76 white $(42.2 \%$ of white women) and 66 black (33.3\%) women. While $57.9 \%$ of osteoporotic white women reported new use of antifracture therapy, new use was reported by only $24.2 \%$ of osteoporotic black women $(P=.002$ on multivariable analysis). This was prescription medicine in only 16 of 76 white women compared with only 8 of 66 black women, $P=$.36. In the presence of prior fracture, only 11 of 79 black women reported antifracture therapy use by year 2 , compared with 41 of 82 white women ( $P=.02$ on multivariable analysis).

\section{DISCUSSION}

We found that use of medications to prevent fracture was low among women with low BMD and clinical risk factors for fracture, despite educational efforts on the part of the Health $\mathrm{ABC}$ Study. Several attributes related to physicans' and patients' view of treatment of low BMD, especially without frank osteoporosis, may explain our findings and give insight into why there are low levels of NOF guideline adherence.

First, it is plausible that some providers are not skilled at DXA interpretation. Use of DXA scan as a screening tool for osteoporosis did not become commonplace until the mid1990s. ${ }^{10,20}$ Guidelines for treatment of people with low BMD did not diffuse from specialty literature to the literature of general medicine and family practice until 1999. ${ }^{21}$ Health ABC provided general education information for patients and physicians, as well as an alert letter for osteoporosis, but specific treatments and therapeutic guidelines were not included. Conversely, Stock and colleagues found that DXA reports that included recommendations for specific therapies sent to primary care doctors resulted in greater antifracture medication initiation. Similarly, interventions that focused on patient-specific physician reminders or patient education at the time of DXA scanning improved osteoporosis screening and therapy. ${ }^{22-25}$

Second, our data provide evidence that there may be failure to integrate important risk factors, such as a history of falls, along with information provided in a DXA scan in the overall prevention of fractures in older adults. In addition, physicians may be uncertain regarding the strength of data behind guideline recommendations for women with risk factors and a $T$ score above $-2.5 .^{26,27}$ We show lower use of an- 
Table 2. New Use of Antifracture Medications in $\mathbf{3 7 8}$ Older Female Health ABC Participants With a National Osteoporosis Foundation Indication for These Agents*

\begin{tabular}{|c|c|c|c|c|}
\hline Demographics and Socioeconomic Status & OR, Univariate & $P$ Values, Univariate & OR, Multivariable ${ }^{\dagger}$ & $P$ Values, Multivariable \\
\hline White race & $3.6(2.3$ to 5.8$)$ & $<.001$ & $2.6(1.5 \text { to } 4.8)^{\ddagger}$ & $<.001$ \\
\hline Age, per y over 70 & - & - & $0.9(0.9$ to 1.0$)$ & .21 \\
\hline Income $>25 \mathrm{~K}$ & $2.0(1.2$ to 3.2$)$ & .006 & $1.0(0.6$ to 1.8$)$ & .98 \\
\hline Drug coverage & $1.8(1.1$ to 2.8$)$ & .02 & $1.6(0.9$ to 2.6$)$ & .08 \\
\hline Education $\geq \mathrm{HS}$ & $2.3(1.3$ to 4.1$)$ & .002 & $1.2(0.6$ to 2.4$)$ & .55 \\
\hline \multicolumn{5}{|l|}{ Health status and comorbid conditions } \\
\hline Osteoporosis & 2.5 (1.6 to 3.9$)$ & $<.001$ & $2.9(1.7 \text { to } 4.7)^{\ddagger}$ & $<.001$ \\
\hline Charlson score $\geq 2$ & $0.7(0.4$ to 1.3$)$ & .28 & $1.0(0.5$ to 1.9$)$ & .93 \\
\hline Slow walking & $0.7(0.5$ to 1.2$)$ & .23 & $1.0(0.5$ to 1.7$)$ & .91 \\
\hline Difficulty rising & $0.8(0.4$ to 1.5$)$ & .49 & $0.7(0.3$ to 1.5$)$ & .28 \\
\hline Previous fracture & $1.2(0.8$ to 1.9$)$ & .65 & $1.3(0.8$ to 2.1$)$ & .40 \\
\hline Fall/12 mo & $1.1(0.6$ to 1.7$)$ & .90 & $1.1(0.6$ to 1.9$)$ & .82 \\
\hline $3 \mathrm{MS}$ score $<80$ & $0.3(0.1$ to 0.7$)$ & .004 & $0.5(0.2$ to 1.5$)$ & .24 \\
\hline Medications > median & $1.3(0.8$ to 2.0$)$ & .25 & $1.4(0.9$ to 2.4$)$ & .17 \\
\hline \multicolumn{5}{|l|}{ Self-efficacy and health behaviors } \\
\hline Low self-efficacy & $1.0(0.3$ to 2.8$)$ & 1.0 & $0.70(0.2$ to 2.3$)$ & .55 \\
\hline Received flu shot & $2.4(1.5$ to 3.9$)$ & $<.001$ & $2.2(1.3 \text { to } 3.8)^{\ddagger}$ & .004 \\
\hline Received mammogram & $0.9(0.4$ to 1.6$)$ & .61 & $0.8(0.4$ to 1.7$)$ & .52 \\
\hline
\end{tabular}

* Mean and standard deviation (SD) for all continuous variables. Odds ratios (OR) are presented with 95\% confidence intervals.

${ }^{\dagger}$ For multivariable analysis, OR after adjustment for all other factors. The c-statistic for the model was 0.75 .

${ }^{\ddagger} \mathrm{P}<.05$.

Health ABC, Health, Aging, and Body Composition; HS, high school, 3MS, Modified Mini-Mental State.

tifracture medications than other studies that have examined use after fracture ${ }^{13,14,28-31}$ or after DXA in women with osteoporosis, ${ }^{32-35}$ even when we include calcium and vitamin D as a therapy. This may be because we examine use consistent with NOF guidelines, in which recommendation for therapy extends to some women with osteopenia. The only randomized, controlled trial showing reduction in nonvertebral fracture in women not chosen for osteoporosis is the Women's Health Initiative. Hormone replacement therapy decreased clinical fracture risk, without significant interaction between lower versus higher BMD cutpoints in the subgroup of women for whom BMD was measured. ${ }^{36}$ Although randomized controlled studies that support treating osteopenic women to prevent nonvertebral fracture are otherwise absent, NOF guideline recommendations for osteopenic women are consistent with the following: fracture risk is associated with BMD in a linear, not a threshold manner; ${ }^{37}$ clinical risk factors contribute to fracture risk, independent of $\mathrm{BMD},{ }^{38}$ and, because there is a higher prevalence of osteopenia in the population, the majority of fractures will occur in women with osteopenia, not osteoporosis. ${ }^{39}$ Recently, NOF guidelines have been validated for long-term clinical fracture prediction. ${ }^{40}$ Yet recommendations for a $T$ score intervention threshold and treating osteopenic women are not without controversy. Other countries set different $T$ score thresholds for therapy, which are generally more conservative than those of the United States. In support of a more conservative threshold, a recent assessment of bisphosphonate therapy in women with osteopenia demonstrated a high cost per quality-adjusted life year gained. However, the cost-effectiveness of bisphosponates in osteopenic women with clinical risks was more acceptable. ${ }^{41}$ Conversely, current debate focuses on absolute fracture risk and not a BMD cutpoint for therapy recommendations. ${ }^{42}$ This focus on clinical risk factors may lead to more osteopenic women being recommended for treatment in the future.

We found that use of antifracture therapy was especially low among African-American women. Data on the relationship between low BMD and fracture, ${ }^{43-45}$ treatment, and fracture prevention $^{4,46,47}$ are largely based on white women. The NOF addresses interventions in postmenopausal white women only. The absence of data may account for the racial differences in medication use. Only this year has BMD been validated for fracture prediction in black women, in whom the strength of association between BMD and fracture is less than in white women after adjusting for other fracture risk factors. ${ }^{48}$ However, even among Medicare recipients with a typical osteoporotic fracture, there are racial differences in subsequent medication use. ${ }^{49}$ We show lower use of antifracture medicines in black women with osteopenia and clinical risks, in those with osteoporosis, and in women with a postmenopausal fracture. Enhancing overall treatment for low BMD and reducing racial disparities in treatment will require a multifactorial approach. This may include better evidence supporting treating African Americans, evidence-based guidelines of treatment of osteopenia in women of all races, and patient-specific and provider-specific interventions to translate these guidelines into appropriate prescribing of antifracture medications.

Low persistence with antifracture treatment may partially explain our findings. Once treatment of osteoporosis has been initiated, there is a high rate of discontinuation of therapy by the patient. ${ }^{15,50}$ Adherence to and persistence with bisphosphonates is linked to patient characteristics, like patient belief that BMD study shows osteoporosis, ${ }^{51}$ younger age, fewer other medications, fewer comorbidities, and prior fracture. ${ }^{15}$ To our knowledge, there are no publications examining factors associated with adherence and persistence with calcium and vitamin D in people with low BMD. We show that use of calcium and vitamin D were low, even though these agents are available without prescription and generally well tolerated.

Our findings must be interpreted in light of several limitations. Our data collection for new use of medications is applicable only through 2000. We do not have data on how many primary care physicians received the DXA reports, nor number of visits with a primary care physician in the 2 years subse- 
quent to DXA testing. We do not have data on physician characteristics. This, however, has been studied, and the only physician factor associated with better osteoporosis guideline adherence was female gender. ${ }^{52}$ Finally, we do not know patients' attitudes toward osteoporosis, fracture risk, or medication use, all of which may influence adherence to antifracture medicine. Racial differences in knowledge of and concern regarding osteoporosis as a personal health risk have been shown in previous work, ${ }^{53-55}$ which may also explain the racial differences in antifracture medicine use in our study.

In conclusion, we found that treatment of healthy older women at risk for fracture was unacceptably low. This was true despite their having guideline-based indications for treatment, and despite the feedback of a DXA report and general education about low BMD to patients and their physicians. Interventions that provide patient-specific information, targeting both patients and providers, should be developed, tested and implemented to improve treatment to reduce the risk of fracture among appropriate treatment candidates. Finally, prospective evaluation of osteoporosis guidelines would be important in demonstrating the utility of these recommendations for older women with osteopenia.

Elizabeth Webb for editorial assistance, Karen Barrow for assistance with organizing data. Drs. Kathryn Ryder and Ron Shorr had full access to the data and are responsible for the accuracy and integrity of the data analysis.

This work was supported by K23 RR 16047 and NIA contract numbers N01-AG-6-2101; N01-AG-6-2103; NO1-AG-6-2106. Author Contributions:

Dr. Ryder: study concept and design, statistical analysis and interpretation, manuscript preparation

Dr. Shorr: study concept and design, manuscript preparation

Dr. Tylavsky: manuscript preparation

Dr. Bush: statistical analysis and interpretation

Dr. Bauer: study design, manuscript preparation

Dr. Simonsick: manuscript preparation

Dr. Strotmeyer: manuscript preparation

Dr. Harris: manuscript preparation.

\section{REFERENCES}

1. Looker AC, Johnston CC Jr, Wahner HW, et al. Prevalence of low femoral bone density in older US women from NHANES III. J Bone Miner Res. 1995; 10:796-802.

2. Kanis JA, Johnell O, Oden A, Dawson A, De Laet C, Jonsson B. Ten year probabilities of osteoporotic fractures according to BMD and diagnostic thresholds. Osteoporos Int. 2001;12:989-95.

3. Black DM, Thompson DE, Bauer DC, et al. Fracture risk reduction with alendronate in women with osteoporosis: the Fracture Intervention Trial. FIT Research Group. J Clin Endocrinol Metab. 2000;85:4118-24.

4. Cummings SR, Black DM, Thompson DE, et al. Effect of alendronate on risk of fracture in women with low bone density but without vertebral fractures: results from the Fracture Intervention Trial. JAMA. 1998;280: 2077-82.

5. Watts NB, Josse RG, Hamdy RC, et al. Risedronate prevents new vertebral fractures in postmenopausal women at high risk. J Clin Endocrinol Metab. 2003;88:542-9.

6. McClung MR, Geusens P, Miller PD, et al. Effect of risedronate on the risk of hip fracture in elderly women. Hip Intervention Program Study Group. N Engl J Med. 2001;344:333-40.

7. Christiansen C, Riis P. Consensus Development Conference. Prevention and treatment of osteoporosis. Nord Med. 1991;106:145-7.

8. AACE clinical practice guidelines for the prevention and treatment of postmenopausal osteoporosis. J Fla Med Assoc. 1996;83:55266.

9. Meunier PJ, Delmas PD, Eastell R, et al. Diagnosis and management of osteoporosis in postmenopausal women: clinical guidelines. Internation- al Committee for Osteoporosis Clinical Guidelines. Clin Ther. 1999;21: 1025-44.

10. Assessment of fracture risk and its application to screening for postmenopausal osteoporosis. Report of a WHO Study Group. World Health Organ Tech Rep Ser. 1994;843:1-129.

11. Physician's Guide to Prevention and Treatment of Osteoporosis. Washington, DC: National Osteoporosis Foundation; 1998.

12. Feldstein A, Elmer PJ, Orwoll E, Herson M, Hillier T. Bone mineral density measurement and treatment for osteoporosis in older individuals with fractures: a gap in evidence-based practice guideline implementation. Arch Intern Med. 2003;163:2165-72.

13. Simonelli C, Chen YT, Morancey J, Lewis AF, Abbott TA. Evaluation and management of osteoporosis following hospitalization for low-impact fracture. J Gen Intern Med. 2003;18:17-22.

14. Siris ES, Bilezikian JP, Rubin MR, et al. Pins and plaster aren't enough: a call for the evaluation and treatment of patients with osteoporotic fractures. J Clin Endocrinol Metab. 2003;88:3482-6.

15. Solomon DH, Avorn J, Katz JN, et al. Compliance with osteoporosis medications. Arch Intern Med. 2005; 165:2414-9.

16. Harris TB, Visser $\mathbf{M}$, Everhart $\mathbf{J}$, et al. Waist circumference and sagittal diameter reflect total body fat better than visceral fat in older men and women. The Health, Aging and Body Composition Study. Ann N Y Acad Sci. 2000;904:462-73.

17. Pahor M, Chrischilles EA, Guralnik JM, Brown SL, Wallace RB, Carbonin P. Drug data coding and analysis in epidemiologic studies. Eur J Epidemiol. 1994;10:405-11.

18. Teng EL, Chui HC. The Modified Mini-Mental State (3MS) examination. J Clin Psychiatry. 1987;48:314-8.

19. Charlson ME, Pompei P, Ales KL, Mackenzie CR. A new method of classifying prognostic comorbidity in longitudinal studies: development and validation. J Chronic Dis. 1987;40:373-83.

20. Miller PD, Bonnick SL, Rosen C. Guidelines for the clinical utilization of bone mass measurement in the adult population. Society for Clinical Densitometry. Calcif Tissue Int. 1995;57:251-2.

21. Mouton CP, Espino DV. Health screening in older women. Am Fam Physician. 1999;59:1835-42.

22. Stock JL, Waud CE, Coderre JA, et al. Clinical reporting to primary care physicians leads to increased use and understanding of bone densitometry and affects management of osteoporosis. A randomized trial. Ann Intern Med. 1998;128:996-9.

23. Cuddihy MT, Amadio PC, Gabriel SE, Pankratz VS, Kurland RL, Melton LJ III. A prospective clinical practice intervention to improve osteoporosis management following distal forearm fracture. Osteoporos Int. 2004; 15:695-700.

24. Feldstein AC, Elmer PJ, Smith DH, et al. Results of a randomized, controlled trial to improve the management of osteoporosis after fracture. J Bone Miner Res. 2003;18(Suppl 2):S268.

25. Majumdar SR, Rowe BH, Folk D, et al. A controlled trial to increase detection and treatment of osteoporosis in older patients with a wrist fracture. Ann Intern Med. 2004;141:366-73.

26. Miller PD. Editorial: greater risk, greater benefit-true or false? J Clin Endocrinol Metab. 2003;88:538-41.

27. Rosen CJ, Brown SA. A rational approach to evidence gaps in the management of osteoporosis. Am J Med. 2005;118:1183-9.

28. Freedman KB, Kaplan FS, Bilker WB, Strom BL, Lowe RA. Treatment of osteoporosis: are physicians missing an opportunity? J Bone Joint Surg Am. 2000;82-A: 1063-70.

29. Cuddihy MT, Gabriel SE, Crowson CS, et al. Osteoporosis intervention following distal forearm fractures: a missed opportunity? Arch Intern Med. 2002;162:421-6.

30. Andrade SE, Majumdar SR, Chan KA, Buist DS, et al. Low frequency of treatment of osteoporosis among postmenopausal women following a fracture. Arch Intern Med. 2003;163:2052-7.

31. Feldstein AC, Nichols GA, Elmer PJ, Smith DH, Aickin M, Herson M. Older women with fractures: patients falling through the cracks of guideline-recommended osteoporosis screening and treatment. J Bone Joint Surg Am. 2003;85-A:2294-302.

32. Fitt NS, Mitchell SL, Cranney A, Gulenchyn K, Huang M, Tugwell P. Influence of bone densitometry results on the treatment of osteoporosis. Can Med Assoc J. 2001;164:777-81.

33. Pressman A, Forsyth B, Ettinger B, Tosteson AN. Initiation of osteoporosis treatment after bone mineral density testing. Osteoporos Int. 2001;12:337-42.

34. Economides PA, Kaklamani VG, Karavas I, Papaioannou GI, Supran S, Mirel RD. Assessment of physician responses to 
abnormal results of bone densitometry studies. Endocrin Pract. 2000;6: 351-6.

35. Brennan RM, Wactawski-Wende J, Crespo CJ, Dmochowski J. Factors associated with treatment initiation after osteoporosis screening. Am J Epidemiol. 2004; 160:475-83.

36. Cauley JA, Robbins J, Chen Z, et al. Effects of estrogen plus progestin on risks of fracture and bone mineral density: the Women's Health Initiative randomized trial. JAMA. 2003;290:1729-38.

37. Miller P. Bone mineral density-clinical use and application. Endocrinol Metab Clinics. 2003;32:159-79.

38. Cummings SR, Nevitt MC, Browner WS, et al. Risk factors for hip fracture in white women. Study of Osteoporotic Fractures Research Group. N Engl J Med. 1995;332:767-73.

39. Kanis JA, Seeman E, Johnell o, et al. The perspective of the International Osteoporosis Foundation on the official positions of the International Society for Clinical Densitometry. Osteoporos Int. 2005; 16 : 456-9.

40. Melton LJ III, Atkinson EJ, Khosla S, Oberg AL, Riggs BL. Evaluation of a prediction model for long-term fracture risk. $J$ Bone Miner Res. 2005;20:551-6.

41. Schousboe T, Nyman JA, Kane RL, Ensrud KE. Cost-effectiveness of Alendronate therapy for osteopenic postmenopausal women. Ann Intern Med. 2005; 142:734-49.

42. Kanis JA, Black D, Cooper C, et al. A new approach to the development of assessment guidelines for osteoporosis. Osteoporos Int. 2002;13: 527-36.

43. Grisso JA, Kelsey JL, Strom BL, et al. Risk factors for falls as a cause of hip fracture in women. The Northeast Hip Fracture Study Group. N Engl J Med. 1991;324:1326-31.

44. Cummings SR, Black DM, Nevitt MC, et al. Bone density at various sites for prediction of hip fractures. The Study of Osteoporotic Fractures Research Group. Lancet. 1993;341:72-5.
45. Schott AM, Cormier C, Hans D, et al. How hip and whole-body bone mineral density predict hip fracture in elderly women: the EPIDOS Prospective Study. Osteoporos Int. 1998;8:247-54.

46. Reginster J, Minne HW, Sorensen OH, et al. Randomized trial of the effects of risedronate on vertebral fractures in women with established postmenopausal osteoporosis. Vertebral Efficacy with Risedronate Therapy (VERT) Study Group. Osteoporos Int. 2000;11:83-91.

47. Ensrud KE, Black DM, Palermo L, et al. Treatment with alendronate prevents fractures in women at highest risk: results from the Fracture Intervention Trial. Arch Intern Med. 1997;157:2617-24.

48. Cauley JA, Lui L-Y, Ensrud KE, et al. Bone mineral density and the risk of incident nonspinal fractures in black and white women. JAMA. 2005;293:2102-8.

49. Solomon DH, Finkelstein JS, Katz JN, Mogun H, Avorn J. Underuse of osteoporosis medications in elderly patients with fractures. Am J Med. 2003; 115:398-400.

50. Caro JJ, Ishak KJ, Huybrechts KF, et al. The impact of compliance with osteoporosis therapy on fracture rates in actual practice. Osteoporos Int. 2004; 15:1003-8.

51. Tosteson AN, Grove MR, Hammond CS, et al. Early discontinuation of treatment for osteoporosis. Am J Med. 2003;115:209-16.

52. Solomon DH, Brookhart MA, Gandhi TK, et al. Adherence with osteoporosis practice guidelines: a multilevel analysis of patients, physician, and practice setting characteristics. Am J Med. 2004;117:919-24.

53. Macdougall LA, Barzilay JI, Helmick CG. The role of personal health concerns and knowledge of the health effects of Hormone Replacement Therapy (HRT) on the ever use of HRT by menopausal women, aged 50-54 years. J Women's Health Gender-Based Med. 1999;8:1203-12.

54. Geller SE, Derman R. Knowledge, beliefs, and risk factors for osteoporosis among African-American and Hispanic women. J Natl Med Assoc. 2001;93:13-21.

55. Unson CG, Fortinsky R, Prestwood K, Reisine S. Osteoporosis medications used by older African-American women: effects of socioeconomic status and psychosocial factors. J Commun Health. 2005;30:281-97. 